\title{
Macroscopic and Histopathological Study of the Placenta - An Essential Resource in Litigation Processes
}

\author{
Nogueira $\mathbf{R}^{1,2,3^{*}}$, Pinto-Ribeiro $\mathrm{F}^{2,3}$, Pereira $\mathbf{S M}^{1}$ and Valente $\mathrm{F}^{4}$ \\ ${ }^{1}$ Pathology Laboratory of CGC Genetics/Centro de Genética Clínica, Porto, Portugal \\ ${ }^{2}$ Life and Health Sciences Research Institute (ICVS), School of Health Sciences (ECS), University of Minho, Portugal \\ 3/CVS/3B's - PT Government Associate Laboratory, Braga/Guimarães, Portugal \\ ${ }^{4}$ Prenatal Diagnosis Unit, Hospital of Vila Nova de Gaia/Espinho (CHVNG/E), Porto, Portugal
}

*Corresponding author: Nogueira R, School of Health Sciences, Campus Gualtar, University of Minho, 4750-057 Braga, Portugal, Tel: +351253604809; Email: rosete.nogueira@ecsaude.uminho.pt

Received Date: Sep 22, 2015; Accepted Date: Nov 28, 2015; Published Date: Nov 30, 2015

Copyright: @2015 Nogueira R, et al. This is an open-access article distributed under the terms of the Creative Commons Attribution License, which permits unrestricted use, distribution, and reproduction in any medium, provided the original author and source are credited.

\section{Abstract}

The pathological study of the placenta is of upmost importance in cases of unexplained fetal/perinatal loss and often these carry litigation implications. Integrating pathological findings and the underlying pathophysiological processes, leading to placental lesions, is fundamental for the evaluation of poor fetal and perinatal outcomes and to distinguish from cases of true negligence.

Keywords: Placenta; Litigation process; Pathology study; Histopathology

\section{Overall Perspective}

Understanding the placental function has been crucial for a clinical and well-founded interpretation of pathological alterations associated with poor obstetric outcomes. The anatomopathological study of the placenta allows the investigation of unforeseen cases of fetal/perinatal loss, while further developing our knowledge of some neonatal diseases. The significance of this study is even greater if one considers that about $3 / 1,000$ children will suffer of some sort of cerebral palsy [1-4]. The increase of litigation processes towards hospitals and obstetricians is a reality and in most cases, the litigant part claims negligence. Setting aside, well documented cases of true negligence, one must consciously and responsibly select cases with pathology associated with a poor obstetric outcome. For this purpose, the study of the placental is fundamental [5]. It is important to note that, the aim of this article is not to describe any epidemiological study of specific cases of placental disorders but, to emphasize that the study of the placenta may reveal undiagnosed or unsuspected pathologies in cases of poor obstetric outcomes that explains and justifies fetal/perinatal loss.

\section{Placental pathological features and adverse fetal outcome}

Implantation anomalies can lead to velamentous cord insertion with or without vasa previa, to placental accrete and/or to placenta previa and it is well documented its relationship with neurological damage and increased risk of fetal loss [6,7].

Placental infarction is a pathological condition of unknown etiology with distinctive features and has been associated with fetal intrauterine growth retardation (IUGR), microcephaly and neurological complications $[1,8]$.
Decidual arteriopathy is a type of injury diagnosed only histologically and usually occurs as result of maternal circulatory disorders, such as pre-eclampsia, hypertension, antiphospholipidic syndrome and thrombophilia. It is also associated with placental poor perfusion and low weight, leading to IUGR $[6,9]$. The period of time that, placental lesions take to evolve and extend, and how they become installed are determining factors for fetal complications. The most common example is the abrupt placenta, a serious condition in which, the time period taken to develop a retroplacental hematoma is crucial for the macroscopic interpretation of the lesion and is critical to understand fetal complications. When fetal death does not occur, neurological damage is usually frequent [2,3]. Similarly, placental infarctions have consequent fetal complications according to the time of occurrence, location, extension and its progression. Massive perivillous fibrin deposition is the main diagnostic features of maternal floor infarction, a placental lesion reported to be as high as 1 of 200 placentas. The cause is unknown but, congenital infection, immunemediated rejection and abnormal extravillous trophoblastic proliferation have been suggested etiologies in part because of its recurrent nature.

Fetal vessel thrombosis is a type of lesion singularly diagnosed with histology and greatly related to prematurity and increased incidence on fetal thrombosis and neonatal neurological complications $[4,8,10]$.

Infections are common and highly contagious situations, with infraclinical rates in $10 \%$ to $15 \%$. It may reach the placenta and fetus in several ways: by ascension from tract vaginal infections, by hematogenous transmission from maternal blood by direct introduction via amniocentesis, chorionic villus sampling and other invasive diagnostic procedure or by direct extensions from infection in the endometrium. It is well known an association with fetal loss and cerebral palsy [7]. Hematogenous infection can result in fetal loss due to anemia following Parvovirus B19 infection or lead to severe fetal disease due to toxoplasmosis and/or cytomelovirus (CMV) infection $[11,12]$. Definitive diagnosis of an infectious disease can be established by histological observation of a characteristic inflammatory infiltrate 
and of pathognomonic viral inclusions associated with CMV and parvovirus infection. When, morphological criteria are not fully present, the study should be completed with immunohistochemistry or other laboratory techniques, such as molecular analysis. The ascending/adjacent infection is a subclinical condition that is present in about $20 \%$ of cases. Of these, histology analysis allows the diagnosis of acute/subacute chorioamnionitis and should always be classified according to the stage, degree and as possible with dating time evolution by the presence of hemosiderin. Chronic chorioamnionitis is a medical condition with pathogenesis not yet determined and diagnosed only with histological examination. This condition has been demonstrated to be associated with maternal hypertension, diabetes, IUGR, oligohydramnios, hydrops fetalis and poor perinatal evolution $[13,14]$.

Massive chronic intervillositis is a medical condition also singularly diagnosed with histology and is associated with IUGR and fetal death and commonly described in recurrent abortions. In $70 \%$ of cases, this condition is present simultaneously with chronic villitis and is related to prematurity and neurological injury [15]. Chronic villitis occurs in $5 \%$ to $10 \%$ of all placentas and higher percentage is well documented when placenta of complicated pregnancies are studied. At times infectious etiology is apparent however, in majority of cases no specific etiology is elicited and the term villitis of unknown etiology (VUE) is used. There are no doubts that VUE is a recurrent lesion with occurrence rates of $10 \%$ to $25 \%$. Two theories are postulated with respect to the etiology of VUE. One suggest that is an infectious disease caused by a yet unrecognized agent and other suggest an immune reaction supported by the preferential localization of these lesion and type of inflammatory cells. VUE is also associated with prematurity, abnormal neurologic development and intra-uterine fetal demise [16].

The etiology of "ADAM complex" (amniotic deformities, adhesions and mutilations) is widely discussed as its incidence is difficult to document and studies suggest a rate of $1 / 2,500$ to $1 / 10,000$ newborns. Amnion rupture will cause, by mechanical way, amniotic bands or sheets, leading to fetal amputations, anomalies or even demise. The amnion rupture etiology is unknown however, it is important to note that this is usually nonrecurring but the fetal pathological condition is presented with a varied pattern related with the time of occurrence and can result in severe malformations if it occurs prematurely, mimicking trisomy 13 phenotype, or minor malformations sometimes not prenatally detected.

On the other hand, the color change in the placenta has a distinct pathogenesis. About $20 \%$ of newborns present a green placenta related to meconium and it is believed that fetal distress is due to vasoconstrictor effect, inducing vascular muscle cell necrosis and compromising the return of the venous oxygenated placental blood $[17,18]$. In premature newborns, the same color can translate in hemosiderin deposits associated with retromembranous hematoma, with risk of fetal-maternal transfusion, fetal hemolysis and thrombocytopenia [19]. In turn, the alteration in parenchyma color reflects the hemoglobin content of the villi and, when pale, usually translates in fetal hydrops/anemia, with heterogeneous etiology and regularly in neurological damage.

Villi morphology when histologically evaluated is correlated with gestational age and deviation from normal development is usually classified as: (i) maturation arrest/delay, reflecting maternal or fetal pathology and (ii) advanced maturity, reflecting poor perfusion and low weight with fetal/neonatal hypoxia and death[15,20]. When fetal death occurs, determining time of death in utero is always important and is based in macroscopic and histological changes of the placenta and fetus $[21,22]$.

Chorangiosis is an alteration that results from an abnormal proliferation and capillary neovascularization process associated with prolonged fetal hypoxia and even though the significance and integration into the fetal-placental unit is not completely understood, recent studies have shown its correlation with perinatal complications [23].

Erythroblastosis usually correlates with hypoxia, infections, bleeding and hemolytic anemia and it can be associated with genetic or epigenetic disorders, being also described as a secondary effect of trauma $[19,24]$.

Fetal injuries in cases of mesenchymal dysplasia are well reported and it is known that about $1-2 \%$ of this change, often unsuspected, is associated with placental mosaicism [25].

The intrinsic placental lesions correspond mostly to primary tumors, where chorangioma is the most frequent and have an increased risk of fetal morbidity/mortality. Gestational trophoblastic diseases are not true neoplasm. However, they are associated with an increased risk for the development of neoplasm, specifically choriocarcinoma. Other gestational trophoblastic disease like placental site nodule and exaggerated placental site, are not grossly identifiable, unlike placental site trophoblastic tumor (PSTT) and epithelioid trophoblastic tumor (ETT) are generally evident as infiltrative masses. Usually these situations do not pose any problem in litigation process. Chorangioma and gestational trophoblastic disease require an appropriate clinical follow-up due to the risk of recurrence and malignancy, or even more aggressive disease like can occurs in PSTT and ETT.

In twin pregnancies, in order to understand the origin of fetal lesions and repercussions, it is essential that the physician provides adequate a referencing of fetal umbilical cord. It is the pathologist's responsibility to document: (i) the relationship between membranes/ division septum and their correlation with the chorionic/vascular equator, and chorionicity; (ii) the presence of vascular anastomosis (VA) with or without criteria for twin-to-twin transfusion syndrome (TTTS) and (iii) the relationship and insertion type of umbilical cords. Both cord's pathology and pathology related to the presence of VA are well documented and understood. Secondary vasculogenic organ damage and destructive lesions can occur in the survivor after fetal death of one twin, particularly in monochorionic twins, while polyhydramnios and oligohydramnios are most frequently found in chronic TTTS and yet justify the discrepancy of fetal growth [25].

\section{What type of placentas should one select for the anatomopathological study?}

Selecting a cohort of placentas to study it is not a consensual matter and may be based on specific clinical criteria, consist in macroscopic examination of all placentas and microscopic study of specific cases or be restricted to cases of fetal/perinatal complications with/without diagnosed or suspected maternal problems $[26,27]$.

It is essential that the selection of placentas is accompanied by the complete clinical information for the diagnostic to be integrated and useful. The obstetrician should gather/provide all relevant clinical information and a list of issues to clarify; while the pathologist is responsible for studying the placenta to establish a diagnosis that 
integrates pathological findings with clinical implications [27-30]. The pathological diagnosis should be integrated considering: (i) maternal age and invasive diagnostic and therapeutic procedures, including medically assisted reproduction techniques; (ii) gestational age and maturation-related deviations and (iii) traumatic injuries, including road traffic accidents, which many times present clinicopathological features similar to other conditions such as abrupt placenta, infarctions, hemorrhagic villitis and/or intra-amniotic hemorrhage $[6,27,31]$.

\section{Conclusion}

The development of standard guidelines and multidisciplinary clinical consensus would allow the establishment of an accurate protocol and reproductive methodologies that would assist in estimating adequate criteria for subsequent actions. Table 1 reports some situations with clinical indication for the anatomopathological study of the placenta [32] (Table 1).

\begin{tabular}{|c|c|c|}
\hline Maternal Diabetes & Fetal/Neonatal & $\begin{array}{l}\text { Placenta, } \\
\text { membranes and } \\
\text { umbilical cords }\end{array}$ \\
\hline $\begin{array}{l}\text { Pregnancy-induced or } \\
\text { chronic hypertension }\end{array}$ & Fetal or neonatal death & $\begin{array}{l}\text { Infarctions, including } \\
\text { infarction of the } \\
\text { placental bed }\end{array}$ \\
\hline $\begin{array}{l}\text { Premature Rupture of } \\
\text { Membranes }\end{array}$ & Twin pregnancy & Placental abruption \\
\hline $\begin{array}{l}\text { Preterm birth } \quad(<36 \\
\text { weeks })\end{array}$ & Prematurity & Vasa previa \\
\hline $\begin{array}{l}\text { Post-term birth (>42 } \\
\text { weeks) }\end{array}$ & $\begin{array}{ll}\text { Intrauterine } & \text { growth } \\
\text { retardation (IUGR) }\end{array}$ & Placenta previa \\
\hline Poor obstetric history & Hydrops & $\begin{array}{l}\text { Any abnormal } \\
\text { appearance of the } \\
\text { umbilical } \\
\text { membranes or of the } \\
\text { placenta }\end{array}$ \\
\hline $\begin{array}{l}\text { Unexplained fever or } \\
\text { infection }\end{array}$ & Congenital anomalies & \\
\hline Oligohydramnios & $\begin{array}{l}\text { Fetal/neonatal } \\
\text { erythroblastosis }\end{array}$ & \\
\hline \multirow[t]{4}{*}{ History of drug use } & $\begin{array}{l}\text { Not reassuring fetal status / } \\
\text { transfer to neonatal care unit }\end{array}$ & \\
\hline & Ominous heart rate & \\
\hline & Meconium discharge & \\
\hline & $\begin{array}{l}\text { Low Apgar score }\left(<5 \text { at } 1^{\prime}\right. \\
\left.\text { and }<7 \text { at } 5^{\prime}\right)\end{array}$ & \\
\hline
\end{tabular}

Table 1: Indications for anatomopathological study of the placenta.

In litigation processes, the pathologist is frequently called upon and questioned to clarify specific pathological processes and their evolution. The progress of infectious, thrombotic/ischemic events and the establishment of fetal time of death are questions frequently requested. These issues are sometimes challenging to assess due to the coexistence of competing injuries, requiring a confident understanding of its pathogenesis and implications. A cautious pathologist should minimize possible errors, always integrating the complexity of processes, thus avoiding an unfounded opinion that may be disputed.
It is essential to establish a good communication conduct between obstetrician and pathologist for the production of a clinically integrated and consistent report.

\section{Keypoints}

The progress on the knowledge and understanding placenta's function and its associated pathophysiological processes has allowed the placenta to become a reflection of intrauterine life.

The placenta's anatomopathological study is fundamental for the integration and comprehension of poor obstetric outcomes and plays an important role in litigation processes.

A functionally and macroscopically normal placenta can coexist with an adverse intrauterine environment and be the cause of fetal loss.

The anatomopathological diagnosis of the placenta should integrate lesions and its progression with consequent clinical implications.

\section{Conflicts of Interest}

The authors declare no conflict of interest.

\section{Acknowledgement}

We thank Professor Jorge Correia-Pinto and Professor Purificação Tavares for reviewing the manuscript and for constructive comments regarding this work.

\section{References}

1. Vinnars MT, Vollmer B, Nasiell J, Papadogiannakis N, Westgren M (2015) Association between cerebral palsy and microscopically verified placental infarction in extremely preterm infants. Acta Obstet Gynecol Scand 94: 976-982.

2. Redline RW (2009) Disorders of placental circulation and the fetal brain. Clin Perinatol 36: 549-559.

3. Redline RW (2006) Placental pathology and cerebral palsy. Clin Perinatol 33: 503-516.

4. Grafe MR (1994) The correlation of prenatal brain damage with placental pathology. J Neuropathol Exp Neurol 53: 407-415.

5. Chang KT (2014) Examination of the placenta: medico-legal implications. Semin Fetal Neonatal Med 19: 279-284.

6. Adams-Chapman I, Vaucher YE, Bejar RF, Benirschke K, Baergen RN, et al. (2002) Maternal floor infarction of the placenta: association with central nervous system injury and adverse neurodevelopmental outcome. J perinatol 22: 236-241.

7. Ohyama M, Itani Y, Yamanaka M, Goto A, Kato K, et al. (2002) Reevaluation of chorioamnionitis and funisitis with a special reference to subacute chorioamnionitis. Hum Pathol 33: 183-190.

8. Furuta K, Tokunaga S, Furukawa S, Sameshima H (2014) Acute and massive bleeding from placenta previa and infants' brain damage. Early Hum Dev 90: 455-458.

9. Mifsud W, Sebire NJ (2014) Placental pathology in early-onset and lateonset fetal growth restriction. Fetal Diagn Ther 36: 117-128.

10. Chau V, McFadden DE, Poskitt KJ, Miller SP (2014) Chorioamnionitis in the pathogenesis of brain injury in preterm infants. Clin Perinatol 41: 83-103.

11. Lamont RF, Sobel JD, Vaisbuch E, Kusanovic JP, Mazaki-Tovi S, et al (2011) Parvovirus B19 infection in human pregnancy. BJOG 118: 175-186.

12. Dijkmans AC, de Jong EP, Dijkmans BA, Lopriore E, Vossen A, et al. (2012) Parvovirus B19 in pregnancy: prenatal diagnosis and management of fetal complications. Curr Opin Obstet Gynecol 24: 95-101. 
Citation: Nogueira R, Pinto-Ribeiro F, Pereira SM, Valente F (2015) Macroscopic and Histopathological Study of the Placenta - An Essential Resource in Litigation Processes. J Clin Res Bioeth 6: 247. doi:10.4172/2155-9627.1000247

Page 4 of 4

13. Kim CJ, Romero R, Chaemsaithong P, Chaiyasit N, Yoon BH, et al. (2015) Acute chorioamnionitis and funisitis: definition, pathologic features, and clinical significance. Am J Obstet Gynecol 213: S29-52.

14. Ericson JE, Laughon MM (2015) Chorioamnionitis: implications for the neonate. Clin Perinatol 42: 155-165.

15. Doss BJ, Greene MF, Hill J, Heffner LJ, Bieber FR, et al. (1995) Massive chronic intervillositis associated with recurrent abortions. Hum Pathol 26: $1245-1251$.

16. Kim CJ, Romero R, Chaemsaithong P, Kim JS (2015) Chronic inflammation of the placenta: definition, classification, pathogenesis, and clinical significance. Am J Obstet Gynecol 213: S53-69.

17. Altshuler G, Arizawa M, Molnar-Nadasdy G (1992) Meconium-induced umbilical cord vascular necrosis and ulceration: a potential link between the placenta and poor pregnancy outcome. Obstet Gynecol 79: 760-766.

18. Kovo M, Schreiber L, Bar J (2013) Placental vascular pathology as a mechanism of disease in pregnancy complications. Thromb Res 131: S18-21.

19. Sikovanyecz J, Horváth E, Pásztor N, Keresztúri A, Szabó J, et al. (2011) Fetomaternal transfusion after amniocentesis and cordocentesis. Ir J Med Sci 180: 697-701.

20. Stanek J (2013) Hypoxic patterns of placental injury: a review. Arch Pathol Lab Med 137: 706-720.

21. Jacques SM, Qureshi F, Johnson A, Alkatib AA, Kmak DC (2003) Estimation of time of fetal death in the second trimester by placental histopathological examination. Pediatric and developmental pathology 6: 226-232.
22. Moore IE (2011) Macerated stillbirth. Fetal and Neonatal Pathology pp 224-239.

23. Altshuler G (1984) Chorangiosis. An important placental sign of neonatal morbidity and mortality. Arch Pathol Lab Med 108: 71-74.

24. Fisher M1 (1989) Acute Rh isoimmunization following abdominal trauma associated with late abruption placenta. Acta Obstet Gynecol Scand 68: 657-659.

25. Stipoljev F, Latin V, Kos M, Miskovic B, Kurjak A (2001) Correlation of confined placental mosaicism with fetal intrauterine growth retardation. A case control study of placentas at delivery. Fetal Diagn Ther 16: 4-9.

26. Spencer MK, Khong TY (2003) Conformity to guidelines for pathologic examination of the placenta. Arch Pathol Lab Med 127: 205-207.

27. Roberts DJ, Oliva E (2006) Clinical significance of placental examination in perinatal medicine. J Mater Fetal Neonatal Med 19: 255-264.

28. Benirschke K (1990) The placenta in the litigation process. Am J Obstet Gynecol 162: 1445-1448.

29. Al-Adnani M, Sebire NJ (2007) The role of perinatal pathological examination in subclinical infection in obstetrics. Best Pract Res Clin Obstet Gynaecol 21: 505-521.

30. Jeffrey IJ (2003) The critical role of perinatal pathology. BJOG 20: 128-130.

31. Kochenour NK (1987) Other causes of fetal death. Clin Obstet Gynecol 30: $312-321$.

32. Lewis S BK (1990) Pathology of the placenta, 2nd edn: Churchill Livingstone. 